\title{
Association between Health-Related Quality of Life and Emotional Problems in Rural Adolescents with Overweight and Obesity
}

\author{
Ariuna S. Kosovtseva, PhD*; Lyubov V. Rychkova, PhD, ScD; Anna V. Pogodina, \\ $\mathrm{PhD}$, ScD; Vladimir M. Polyakov, PhD, ScD; Zhanna G. Ajurova, PhD \\ Scientific Centre for Family Health and Human Reproduction Problems \\ Irkutsk, the Russian Federation
}

\begin{abstract}
Background: Health-related quality of life (HRQL) and emotional functioning are important parameters of weight-loss motivation. The aim of this study was to identify the association between emotional/personal characteristics and HRQL in adolescents with overweight and obesity.

Methods and Results: Our cross-sectional case-control study included 172 adolescents: 19 of them overweight, 67 obese, and 86 healthy. We measured anthropometry and performed a psychological examination (PedsQL 4.0, The State-Trait Anxiety Inventory, Buss-Durkee Hostility Inventory, and Personality inventory Mini-SMIL). Negative correlations prevailed between PedsQL scales and psychological traits of healthy adolescents: increases in anxiety, covert anger, and depression were associated with a decrease of HRQL (Total Scale Scores, Psychosocial Health Score, Physical Health Score, and Emotional, Social and School functioning). The psychological impairment (Irritability, Resentment, Guilt, Covert anger) positively correlated with a change in HRQL (Total Scale Scores, Psychosocial Health Score, and Physical Health Score) in obese adolescents.

Conclusion: Obese adolescents had an inadequate association between HRQL and emotional state: the accumulation of anxiety and aggression was accompanied by an increase in HRQL. These difficulties can be a barrier to having treatment and weight-loss motivation.(International Journal of Biomedicine. 2020;10(4):442-447.)
\end{abstract}

Key Words: anxiety $\bullet$ anger $\bullet$ emotion $\bullet$ weight-loss motivation

\section{Abbreviations}

BW, body weight; BMI, body mass index; HRQL, health-related quality of life

\section{Introduction}

Childhood obesity is one of the most prevalent health problems; it is associated with a high risk of obesity outcomes, ${ }^{(1)}$ including a decrease in psychological well-being. It has been established that there is an association between children's overweight/obesity and some mental health problems, including anxiety, ${ }^{(2-4)}$ aggression and depression, ${ }^{(5,6)}$ dissatisfaction with the body, ${ }^{(7,8)}$ low self-esteem, ${ }^{(9)}$ and some

*Corresponding author: Ariuna S. Kosovtseva, PhD. Scientific Centre for Family Health and Human Reproduction Problems, Irkutsk, the Russian Federation.E-mail: arjuna6402@mail.ru behavioral problems. ${ }^{(10)}$ Moreover, previously we have found that obesity in adolescents is associated with decreased HRQL scores. $^{(11)}$

HRQL is an important parameter of well-being, because being obese creates psychological stress for children. It has been established that severely obese children and adolescents have lower HRQL than children and adolescents who are healthy and that they have a quality of life similar to those diagnosed with cancer. ${ }^{(12)}$ Usually, a specific level of HRQL is described in groups of obese and healthy children. ${ }^{(13)}$ A number of studies have shown the relationship between emotional disorders and HRQL in adult obese patients, ${ }^{(14)}$ but we have not found data about a relationship between emotional traits and HRQL in rural adolescents with overweight and obesity. 
Because an emotional eating style can contribute to psychological problems and can play a considerable role in increased appetite, ${ }^{(15)}$ it is important to know the emotional status of adolescents with overweight and obesity. We suggest that adequate perception of weight, well-being, and emotional functioning determines the motivation to lose weight. We do not exclude that obesity contributes to psychological problems, but in this study, we consider a model of externalizing behavioral problems, which indicates that emotional and personal problems might foster weight gain. ${ }^{(16)}$

Thus, the hypothesis for our study: Emotional status is associated with the HRQL in overweight and obese adolescents; namely, emotional problems may deform the perception of well-being and illness, hence reducing the motivation to lose weight. In this regard, the aim of this study was to identify the association between emotional/personal characteristics and HRQL in adolescents with overweight and obesity.

\section{Materials and Methods}

\section{Study design}

We conducted a cross-sectional case-control study of adolescents living in rural areas of the Republic of Buryatia (RB) within an annual medical examination. A total of 1,456 adolescents (11-17 years) were surveyed by the continuous sampling method. Each adolescent was given an anthropometric examination that included linear growth, height, BW, BMI. According to the results of the examination, overweight and obesity were diagnosed in 86 adolescents. To achieve the purpose of the study, a control group of adolescents with normal weight was formed from the same population sample, comparable in age and sex $(\mathrm{n}=86)$. Thus, the analyses included a total of 172 subjects.

Criteria for inclusion in the study were: 1) subjects aged between 11 and 17 years; 2) voluntary informed consent of adolescents over 15 years old, parents/legal representatives of adolescents to participate in the study. Exclusion criteria for the study were: 1) weight deficit (BMI z-scores $<5^{\text {th }}$ percentile); 2) patients or their parents unable to provide the requested information. The study was performed in the territory of 9 out of 15 municipal areas of the RB. Participants were recruited from all adolescents (continuous sampling) who had passed the annual scheduled medical examination.

Procedures and measures

This study included measurement of such anthropometric parameters as linear growth, height, BW, BMI. BW was considered excessive with a BMI $>85^{\text {th }}$ percentile of distribution for a given sex and age, obesity was established with BMI $>95^{\text {th }}$ percentile. BMI values were reformed using BMI z-scores. Height and weight parameters of participants were evaluated using reference values of the WHO AnthroPlus calculator.

Psychological assessment of the protocol research was performed in a group format in the classroom. Each adolescent was asked to complete the following questionnaires:

1.The State-Trait Anxiety Inventory (STAI) - the Russian version, adapted by Khanin. ${ }^{(17)}$ The Trait and State scales measure trait and situational anxiety, respectively.

2. Buss-Durkee Hostility Inventory (BDHI) - the
Russian version adapted and standardized by Khvan et al. ${ }^{(18)}$ The BDHI is a 75-item, self-report inventory intended to measure aspects of anger/hostility and aggression. The BDHI comprises subscales labeled Assault, Indirect, Irritability, Negativism, Resentment, Suspicion, Guilt, and Verbal aggression. As a result, two factors are analyzed: Covert anger/Neurotic aspects of hostility (Suspicion+Resentment) and Overt anger/Behavioral-expressive aspects of hostility (Indirect+Assault+Verbal).

3. Personality inventory Mini-SMIL consists of 65 questions and assesses different personality traits. ${ }^{(19)}$ The MiniSMIL is made up 10 subscales, which are a result of answering certain questions on the test: Scale 1 (Hypochondria), Scale 2 (Depressive symptoms), Scale 3 (Emotional and vegetative instability), Scale 4 (Ambitiousness and irritability), Scale 5 (Masculinity-Femininity), Scale 6 (Stubbornness: suspiciousness, paranoia), Scale 7 (Anxiety), Scale 8 (Odd thinking, social alienation), Scale 9 (Level of excitability, hypomania), and Scale 0 (Introversion).

4. HRQL was measured by using the validated Pediatric Quality of Life Inventory 4.0 Generic Core Scales (PedsQL). ${ }^{(20)}$ The PedsQL is a 23-item age-specific survey. This questionnaire assesses physical, emotional, social, and school functioning, from which total, physical, and psychosocial health summary scores are derived.

The study was carried out in compliance with Ethical Principles for Medical Research Involving Human Subjects, Adopted by the 18th WMA General Assembly, Helsinki, Finland, June 1964, and amended by the 64th WMA General Assembly, Fortaleza, Brazil, October 2013. The study was approved by the Ethics Committee of the Scientific Center for Family Health and Human Reproduction Problems. Written informed consent was obtained from each patient.

Statistical analysis was performed using STATISTICA 6.1 software (Stat-Soft Inc., USA). The normality of distribution of continuous variables was tested by one-sample Kolmogorov-Smirnov test. Baseline characteristics were summarized as frequencies and percentages for categorical variables and as mean \pm standard deviation (SD) for continuous variables. Multiple comparisons were performed with one-way ANOVA with Tukey's pairwise comparisons. The frequencies of categorical variables were compared using Pearson $\chi^{2}$ Spearman's rank correlation coefficient was calculated to measure the strength and direction of the relationship between two variables. A probability value of $P<0.05$ was considered statistically significant.

\section{Results}

Table 1 displays the demographic and anthropometric data of adolescents with normal BW, overweight, and obesity. There were significant differences between adolescents with normal $\mathrm{BW}$, overweight, and obesity with regard to weight, BMI, and z-scores BMI. All these indicators were most high in adolescents with obesity.

Table 2 shows the mean scores on the scales of psychological questionnaires for adolescents. Only two scales of personality inventory Mini-SMIL were significantly 
different: the Scale 5 score was less in obese adolescents than in adolescents with normal BW. The Scale 0 score was lower in a group of overweight adolescents than in healthy adolescents. The scores of other scales and subscales did not significantly differ.

Table 1.

Demographic and clinical features for adolescents with normal $B W$, overweight, and obesity

\begin{tabular}{|l|c|c|c|c|}
\hline \multicolumn{1}{|c|}{ Variable } & $\begin{array}{c}\text { Normal BW } \\
(1)\end{array}$ & $\begin{array}{c}\text { Overweight } \\
(2)\end{array}$ & $\begin{array}{c}\text { Obesity } \\
(3)\end{array}$ & $P$-value \\
\hline Age, yrs & $14.11 \pm 1.78$ & $13.73 \pm 2.23$ & $13.89 \pm 1.85$ & 0.6321 \\
\hline Boys, n (\%) & $48(55.56)$ & $10(52.63)$ & $46(68.66)$ & 0.150 \\
\hline Height, cm & $161.55 \pm 9.77$ & $162.87 \pm 9.05$ & $163.1 \pm 12.27$ & 0.6566 \\
\hline Weight, kg & $52.33 \pm 9.71$ & $62.92 \pm 11.93$ & $78.97 \pm 15.86$ & $\begin{array}{l}\mathrm{P}_{1-2}=0.000034 \\
\mathrm{P}_{1-3}=0.0000 \\
\mathrm{P}_{2-3}=0.0000\end{array}$ \\
\hline BMI, kg/m² & $19.91 \pm 2.47$ & $23.71 \pm 3.05$ & $29.42 \pm 3.67$ & $\begin{array}{l}\mathrm{P}_{1-2}=0.0000 \\
\mathrm{P}_{1-2}=0.0000 \\
\mathrm{P}_{1-3}=0.0000 \\
\mathrm{P}_{2-3}=0.0000\end{array}$ \\
\hline z-scores BMI, & $0.07 \pm 0.64$ & $1.50 \pm 0.36$ & $2.51 \pm 0.55$ & $\begin{array}{l}\mathrm{P}_{1-2}=0.0000 \\
\mathrm{P}_{1-3}=0.0000 \\
\mathrm{P}_{2-3}=0.0000\end{array}$ \\
\hline
\end{tabular}

Table 3 demonstrates HRQL by PedsQL for adolescents. After assessing the differences between the 3 groups, we carried out a pairwise comparison. There were no significant differences in the level of PedsQL scales between adolescents with overweight and normal BW and obesity. The scores of Total HRQL and other subscales, except for Emotional functioning, were significantly lower for obese adolescents than for adolescents with normal BW.

Correlations between HRQL and psychological features in adolescents with different weight category

Spearman correlations between PedsQL scores and psychological parameters of the normal weight, overweight and obese adolescents are reported in Table 4. Opposite tendencies of these correlations were identified in groups with different BW.

Negative significant correlations prevailed between PedsQL scales and psychological features in adolescents with normal BW. For example, all summary scales, such as Total Scale Scores, Psychosocial Health Score, and Physical Health Score are associated with BDHI-Resentment, BDHISuspicion, BDHI-Covert anger, STAI-state subscale, and STAI-trait subscale. Besides, these PedsQL Summary Scales are correlated with such Mini-SMIL scales as Scale 2, Scale 4, Scale 6, Scale 7, Scale 8, and Scale 0. Thus, an increase in anxiety, covert anger, resentment, depressive symptoms, introversion, and other features are associated with a decrease in the subscales of HRQL (Total Scale Scores, Psychosocial Health Score, Physical Health Score, and Emotional, Social and School functioning) in adolescents with normal BW.

The STAI-trait subscale is significantly correlated (inverse association) with the Physical Health Score ( $\mathrm{r}=$ 0.714). An increase in BDHI (Negativism) is associated with
Table 2.

Scores on psychological measures for adolescents with normal BW, overweight, and obesity

\begin{tabular}{|c|c|c|c|c|}
\hline $\begin{array}{l}\text { Psychological } \\
\text { subscales }\end{array}$ & $\underset{\text { (1) }}{\text { Normal BW }}$ & $\begin{array}{c}\text { Overweight } \\
\text { (2) }\end{array}$ & $\begin{array}{l}\text { Obesity } \\
\text { (3) }\end{array}$ & $P$-value \\
\hline STAI-state subscale & $38.68 \pm 9.93$ & $36 \pm 7.52$ & $39 \pm 1.41$ & 0.2961 \\
\hline STAI-trait subscale & $40.88 \pm 10.54$ & $41.86 \pm 7.95$ & $41.5 \pm 13.44$ & 0.9174 \\
\hline BDHI (Assault) & $4.75 \pm 2.19$ & $4.61 \pm 1.88$ & $4.94 \pm 2$ & 0.7768 \\
\hline BDHI (Indirect) & $3.68 \pm 1.62$ & $3.56 \pm 1.98$ & $3.87 \pm 1.53$ & 0.6791 \\
\hline BDHI (Irritability) & $4.71 \pm 2.27$ & $4.28 \pm 2.49$ & $4.28 \pm 2.22$ & 0.4656 \\
\hline BDHI (Negativism) & $2.35 \pm 1.3$ & $2.47 \pm 1.12$ & $2.6 \pm 1.35$ & 0.5006 \\
\hline BDHI (Resentment) & $3.7 \pm 2$ & $3.78 \pm 1.35$ & $3.7 \pm 1.66$ & 0.9837 \\
\hline BDHI (Suspicion) & $4.7 \pm 1.83$ & $5.06 \pm 2.33$ & $4.85 \pm 1.51$ & 0.6937 \\
\hline BDHI (Guilt) & $5.8 \pm 2.08$ & $6.44 \pm 1.42$ & $6 \pm 2.13$ & 0.4508 \\
\hline $\begin{array}{l}\text { BDHI } \\
\text { (Verbal } \\
\text { aggression) }\end{array}$ & $5.89 \pm 2.43$ & $6.67 \pm 2.05$ & $6.02 \pm 2.52$ & 0.4496 \\
\hline BDHI (Covert anger) & $8.33 \pm 3.25$ & $8.83 \pm 2.9$ & $8.22 \pm 2.5$ & 0.7266 \\
\hline $\begin{array}{l}\text { BDHI (Over } \\
\text { anger) }\end{array}$ & $15.19 \pm 5.25$ & $15.56 \pm 3.82$ & $15.01 \pm 5.48$ & 0.9184 \\
\hline Mini-SMIL Scale 1 & $55.74 \pm 10.78$ & $58.33 \pm 11.93$ & $55.85 \pm 6.7$ & 0.5491 \\
\hline Mini-SMIL Scale 2 & $54.26 \pm 10.78$ & $51.67 \pm 11.93$ & $51.71 \pm 9.46$ & 0.2761 \\
\hline Mini-SMIL Scale 3 & $57.96 \pm 9.84$ & $59.17 \pm 9$ & $55.85 \pm 9.48$ & 0.2690 \\
\hline Mini-SMIL Scale 4 & $465.19 \pm 9.9$ & $62.5 \pm 12.15$ & $64.63 \pm 9.77$ & 0.5771 \\
\hline Mini-SMIL Scale 5 & $60.76 \pm 9.87$ & $55 \pm 13.82$ & $55.37 \pm 9.51$ & $\begin{array}{l}\mathrm{P}=0.0026 \\
\mathrm{P}_{1-2}=0.0705 \\
\mathrm{P}_{1-3}=0.0042 \\
\mathrm{P}_{2-3}=0.9894\end{array}$ \\
\hline Mini-SMIL Scale 6 & $60.69 \pm 13.9$ & $62.5 \pm 14.85$ & $61.46 \pm 12.95$ & 0.8536 \\
\hline Mini-SMIL Scale 7 & $758.33 \pm 12.93$ & $53.33 \pm 11.55$ & $58.53 \pm 13.52$ & 0.2770 \\
\hline Mini-SMIL Scale 8 & $62.22 \pm 14.75$ & $55 \pm 14.46$ & $60.24 \pm 13.71$ & 0.1355 \\
\hline Mini-SMIL Scale 9 & $75.46 \pm 12.78$ & $78.33 \pm 10.3$ & $79.27 \pm 11.49$ & 0.1428 \\
\hline Mini-SMIL Scale 0 & $59.07 \pm 14.37$ & $48.18 \pm 8.74$ & $53.29 \pm 13$ & $\begin{array}{l}\mathrm{P}=0.0017 \\
\mathrm{P}_{1-2}=0.0052 \\
\mathrm{P}_{1-3}=0.0262 \\
\mathrm{P}_{2-3}=0.3181\end{array}$ \\
\hline
\end{tabular}

Table 3.

Total and Subscales Scores PedsQL for adolescents with normal $B W$ and obesity

\begin{tabular}{|l|c|c|c|}
\hline \multicolumn{1}{|c|}{ PedsQL subscales } & $\begin{array}{c}\text { Normal BW } \\
(\mathrm{n}=86)\end{array}$ & $\begin{array}{c}\text { Obesity } \\
(\mathrm{n}=67)\end{array}$ & $P$-value \\
\hline Physical health score & $86.31 \pm 13.93$ & $80.6 \pm 17.38$ & 0.0255 \\
\hline Psychosocial Health Score & $78.43 \pm 13.03$ & $72.54 \pm 13.79$ & 0.0076 \\
\hline Emotional functioning & $72.66 \pm 17.64$ & $68.43 \pm 17.52$ & 0.1420 \\
\hline Social functioning & $87.55 \pm 13.71$ & $80.52 \pm 15.91$ & 0.0039 \\
\hline School functioning & $75.06 \pm 17.14$ & $68.66 \pm 16.27$ & 0.0205 \\
\hline Total Scale Score & $81.18 \pm 11.95$ & $75.34 \pm 14.04$ & 0.0062 \\
\hline
\end{tabular}

an increase in Psychosocial Health Score $(\mathrm{r}=0.501)$. The Mini-SMIL Scale 9 is protective in relation to Physical Health Score. In this way, the direction of correlation in overweight patients is changing. These changes are not very pronounced, but are statistically significant. 
Table 4.

Spearman's correlation coefficients between PedsQL scores and BDHI, STAI, Mini-SMIL scores

\begin{tabular}{|c|c|c|c|c|c|c|}
\hline & Total Scale Score & PhH score & PsH Score & $\mathrm{EF}$ & SoF & $\mathrm{SchF}$ \\
\hline \multicolumn{7}{|c|}{ Adolescents with normal BW } \\
\hline $\begin{array}{l}\text { BDHI } \\
\text { (Assault) }\end{array}$ & 0.151 & -0.14 & 0.127 & 0.098 & $0.180^{*}$ & 0.046 \\
\hline BDHI (Irritability) & $-0.212 *$ & $-0.208 *$ & -0.162 & $-0.225 *$ & -0.016 & -0.13 \\
\hline BDHI (Resentment) & $-0.247 *$ & $-0.254^{\wedge}$ & $-0.192 *$ & $-0.249 *$ & $-0.182 *$ & -0.09 \\
\hline BDHI (Suspicion) & $-0.247^{*}$ & $-0.177^{*}$ & $-0.22 *$ & $-0.224 *$ & -0.145 & $-0.214 *$ \\
\hline BDHI (Guilt) & $-0.213^{*}$ & -0.15 & $-0.193 *$ & $-0.273^{\wedge}$ & -0.126 & -0.109 \\
\hline $\begin{array}{l}\text { BDHI } \\
\text { (Covert anger) }\end{array}$ & $-0.296^{\wedge}$ & $-0.242 *$ & $-0.263^{\wedge}$ & $-0.304^{\wedge}$ & $-0.178^{*}$ & $-0.189 *$ \\
\hline STAI-state subscale & $-0.431^{\wedge}$ & $-0.302^{\wedge}$ & $-0.459^{\wedge}$ & $-0.447^{\wedge}$ & $-0.35^{\wedge}$ & $-0.304 *$ \\
\hline STAI-trait subscale & $-0.414^{\wedge}$ & $-0.276^{\wedge}$ & $-0.446^{\wedge}$ & $-0.428^{\wedge}$ & $-0.342^{\wedge}$ & $-0.336^{\wedge}$ \\
\hline $\begin{array}{l}\text { Mini-SMIL, } \\
\text { Scale } 1\end{array}$ & $-0.22 *$ & $-0.247 *$ & -0.156 & $-0.212^{*}$ & $-0.207^{*}$ & 0.025 \\
\hline $\begin{array}{l}\text { Mini-SMIL, } \\
\text { Scale } 2\end{array}$ & $-0.363^{\wedge}$ & $-0.31^{\wedge}$ & $-0.354^{\wedge}$ & $-0.326^{\wedge}$ & $-0.272^{\wedge}$ & $-0.288^{\wedge}$ \\
\hline $\begin{array}{l}\text { Mini-SMIL, } \\
\text { Scale } 4\end{array}$ & $-0.258^{*}$ & $-0.224 *$ & $-0.211 *$ & -0.191 & -0.062 & $-0.259 *$ \\
\hline $\begin{array}{l}\text { Mini-SMIL, } \\
\text { Scale } 6\end{array}$ & $-0.221 *$ & $-0.216^{*}$ & $-0.21 *$ & $-0.206^{*}$ & -0.077 & -0.166 \\
\hline $\begin{array}{l}\text { Mini-SMIL, } \\
\text { Scale } 7\end{array}$ & $-0.342^{\wedge}$ & $-0.27 *$ & $-0.321^{\wedge}$ & $-0.341^{\wedge}$ & $-0.23 *$ & -0.173 \\
\hline $\begin{array}{l}\text { Mini-SMIL, } \\
\text { Scale } 8\end{array}$ & $-0.302^{\wedge}$ & $-0.2 *$ & $-0.289^{\wedge}$ & $-0.278^{\wedge}$ & -0.188 & -0.184 \\
\hline $\begin{array}{l}\text { Mini-SMIL, } \\
\text { Scale } 0\end{array}$ & $-0.276^{\wedge}$ & $-0.295^{\wedge}$ & $-0.241 *$ & $-0.255^{*}$ & $-0.238^{*}$ & -0.105 \\
\hline \multicolumn{7}{|c|}{ Adolescents with overweight } \\
\hline BDHI (Negativism) & 0.444 & 0.462 & $0.501 *$ & $0.546^{*}$ & 0.342 & 0.267 \\
\hline STAI-trait subscale & -0.605 & $-0.714 *$ & -0.236 & -0.271 & -0.676 & -0.333 \\
\hline $\begin{array}{l}\text { Mini-SMIL, } \\
\text { Scale } 9\end{array}$ & 0.406 & $0.588^{*}$ & 0.335 & 0.297 & 0.468 & 0.436 \\
\hline \multicolumn{7}{|c|}{ Adolescents with obesity } \\
\hline BDHI (Irritability) & $0.331 *$ & 0.064 & $0.35^{*}$ & -0.092 & $0.424^{\wedge}$ & 0.125 \\
\hline BDHI (Resentment) & $0.36^{*}$ & $0.332 *$ & $0.369^{*}$ & 0.251 & $0.371^{*}$ & 0.126 \\
\hline BDHI (Guilt) & $0.355^{*}$ & $0.35^{*}$ & $0.392 *$ & 0.221 & $0.432^{\wedge}$ & 0.228 \\
\hline $\begin{array}{l}\text { BDHI } \\
\text { (Covert anger) }\end{array}$ & $0.357 *$ & $0.326^{*}$ & $0.384^{*}$ & 0.212 & $0.375^{*}$ & 0.274 \\
\hline $\begin{array}{l}\text { Mini-SMIL, } \\
\text { Scale } 9\end{array}$ & -0.231 & -0.178 & $-0.311^{*}$ & -0.129 & -0.301 & -0.287 \\
\hline
\end{tabular}

PhH, Physical Health; PsH, Psychosocial Health; EF, Emotional Functioning; SoF, Social Functioning; SchF, School Functioning;

*-Spearman's correlation $P<0.05$; ^- Spearman's correlation $P<0.005$.

The changes in psychological functioning positively and significantly correlate with change in HRQL in adolescents with obesity. For example, Total Scale Scores, Psychosocial Health Score, Physical Health Score are associated with BDHI (Resentment), BDHI (Guilt), BDHI (Covert anger). Besides, a negative significant correlation has been found between Psychosocial Health Score and the Mini-SMIL Scale 9. Thus, we detected the opposite direction of associations between psychological features and HRQL in adolescents with obesity, compared with adolescents with normal BW.
In the first stage of this study, we found that obese adolescents differ from healthy peers in the way their interact with society: They are more masculine and aggressive. Moreover, obese adolescents are more extroverted than overweight adolescents. Our results are in good agreement with the results of other researchers who identified that extraversion is associated with obesity in children. ${ }^{(21)}$ Behavioral differences between introverts and extroverts are associated with selfregulation of excitation.(22) Particularly, more introverted individuals tend to control and reduce excitation levels, while 
extroverts can further increase their arousal level through food intake. ${ }^{(23)}$ The main idea in the concept of self-regulation is the ability to distinguish impulses, as well as to control behavior in a negative situation, and to follow rules or suppress immediate desires, and finally to delay gratification. ${ }^{(24,25)}$ In this way, psychological and emotional disorders and obesity have a common genetic basis, consisting in the regulation of monoamines and peptides, including serotonin, norepinephrine, dopamine, and corticotropin-releasing hormone. ${ }^{(26)}$

The second objective of this study was to identify HRQL differences in adolescents with different body weight. Our results show that only HRQL in the domain of Emotional functioning did not significantly differ between obese and healthy adolescents. Our data are consistent with the results of a study in Kuwait. ${ }^{(27)}$ However, other studies conducted on urban children have shown a decrease in all domains of HRQL in obese adolescents, in comparison with healthy adolescents. ${ }^{(28,29)}$ According to our results, the HRQL decreases in adolescents with obesity, but not in those who are overweight. Consequently, a large increase in BW significantly reduces $\mathrm{HRQL}$, which is consistent with data found in the literature. ${ }^{(12)}$

The third, and main, aim of this study was to identify the relationship between psychological features and HRQL in obese, overweight, and healthy adolescents. Negative significant correlations prevailed between PedsQL scales and psychological features in healthy adolescents. An increase in Anxiety, Covert anger, Resentment, Depressive symptoms, and Introversion was associated with a decrease in the subscales of HRQL (Total Scale Scores, Psychosocial Health Score, Physical Health Score, Emotional, Social and School functioning) in healthy adolescents. Comparable results were obtained in a group of overweight adolescents.

Meanwhile, in obese adolescents, the direction of correlation is changing in the opposite direction. The rise in aggression parameters positively correlated with changes in Total Scale Score, Psychosocial Health Score, and Physical Health Score. The level of excitability negatively correlated with Psychosocial Health Score; consequently, the level of excitability can be a protector from psychosocial functioning dissatisfaction. The process of false quality of life assessing occurs through the negative evaluation of one's own emotions and wrong assessment of the behavior and emotions of other people. The direct association between the accumulation of aggressive emotions and the increase in HRQL might be the result of errors in the evaluation and understanding of one's own emotions and failure. Incorrect interpretation of their own emotions does not allow adolescents to understand the psychological causes of eating disorders. This fact can significantly distort the awareness of the psychological causes of increased appetite and reduce the motivation for weight loss.

Several factors increase the strength of our results: the analysis of a general population sample of obese and overweight adolescents living in rural areas of the RB; the use of well-validated psychological questionnaires; the high participation rate, which minimizes sample selection bias. However, there are several limitations of this study, which should be noted. First, we analyzed a non-clinical sample of healthy, overweight, and obese children, except for a clinical sample of severely obese patients seeking treatment in a specific department. A sample of severely obese patients has more complicated pathologies, including greater psychological distress and more eating disorders. Further research is needed to examine all these categories of adolescents with different BW in order to identify the dynamics of HRQL, psychological and psychopathological changes, and their interactions depending on extreme weight gain in adolescents. Second, we have not analyzed the parents' version of PedsQL, which is filled out by the parents. An analysis of the parents' perception of the obese adolescent's quality of life might complete our knowledge about parental attitudes to childhood obesity in a population. Third, the cross-sectional design does not allow for making predictions and it will be important to conduct a longitudinal study of the relationship between emotions and HRQL.

Despite these limitations, our study confirms the close relationship between a psychological statement and HRQL in obese adolescents. Based on the present findings, we suggest a more direct focus on the study of obese adolescent's psychological and emotional characteristics, or a need for understanding the reasons for aggression and coping behavior to improve the emotional well-being, quality of life, and motivation to lose weight. If psychological problems are a barrier to having recommendations and treatment, then psychological interventions should follow. ${ }^{(30)}$

Summarizing these results, we can conclude that obese and healthy adolescents have opposite directions in the relationship between emotional/personal characteristics and HRQL. In healthy adolescents, the HRQL changes demonstrate an adequate level according to their emotional state. In adolescents with obesity, the accumulation of aggressive emotions is accompanied by an increase in the HRQL. It may be the main reason for weight gain. This fact requires targeted psychological preventive work with overweight and obese adolescents, aimed at treating the psychological causes of increased appetite and the rise of motivation to lose weight.

\section{Competing Interests}

The authors declare that they have no competing interests.

\section{References}

1. Atay Z, Bereket A. Current status on obesity in childhood and adolescence: Prevalence, etiology, co-morbidities and management. Obesity Medicine. 2016;3:1-9. doi: 10.1016/j. obmed.2016.05.00.5

2. Topçu S, Orhon FŞ, Tayfun M, Uçaktürk SA, Demirel F. Anxiety, depression and self-esteem levels in obese children: a case-control study. J Pediatr Endocrinol Metab. 2016 Mar;29(3):357-61. doi: 10.1515/jpem-2015-0254.

3. Fox CK, Gross AC, Rudser KD, Foy AM, Kelly AS. Depression, Anxiety, and Severity of Obesity in Adolescents: Is Emotional Eating the Link? Clin Pediatr (Phila). 2016 Oct;55(12):1120-5. doi: 10.1177/0009922815615825.

4. Sheinbein DH, Stein RI, Hayes JF, Brown ML, Balantekin KN, Conlon RPK, Saelens BE, Perri MG, Welch RR, 
Schechtman KB, Epstein LH, Wilfley DE. Factors associated with depression and anxiety symptoms among children seeking treatment for obesity: A social-ecological approach. Pediatr Obes. 2019 Aug;14(8):e12518. doi: 10.1111/ijpo.12518.

5. Tso M, Rowland B, Toumbourou JW, Guadagno BL. Overweight or obesity associations with physical aggression in children and adolescents: a meta-analysis. Int J Behav Dev. 2017;42(1):116-131. doi: 10.1177/0165025417690265.

6. Derks IPM, Bolhuis K, Yalcin Z, Gaillard R, Hillegers MHJ, Larsson $\mathrm{H}$, Lundström $\mathrm{S}$, Lichtenstein $\mathrm{P}$, van Beijsterveldt CEM, Bartels M, Boomsma DI, Tiemeier H, Jansen PW. Testing Bidirectional Associations Between Childhood Aggression and BMI: Results from Three Cohorts. Obesity (Silver Spring). 2019 May;27(5):822-829. doi: 10.1002/oby.22419.

7. Liu W, Lin R, Guo C, Xiong L, Chen S, Liu W. Prevalence of body dissatisfaction and its effects on health-related quality of life among primary school students in Guangzhou, China. BMC Public Health. 2019 Feb 20;19(1):213. doi: 10.1186/ s12889-019-6519-5.

8. Lee KS, Vaillancourt T. Body mass index, peer victimization, and body dissatisfaction across 7 years of childhood and adolescence: Evidence of moderated and mediated pathways. Dev Sci. 2019 Mar;22(2):e12734. doi: 10.1111/desc. 12734 .

9. Griffiths LJ, Parsons TJ, Hill AJ. Self-esteem and quality of life in obese children and adolescents: a systematic review. Int J Pediatr Obes. 2010 Aug;5(4):282-304. doi: 10.3109/17477160903473697.

10. Thomaseo Burton E, Jones TL, Smith WA, Han JC. Psychosocial Functioning After One Year of Interdisciplinary Pediatric Weight Management. Behav Med. 2020 AprJun;46(2):92-99. doi: 10.1080/08964289.2019.1570073.

11. Pogodina A, Rychkova L, Kravtzova O, Klimkina J, Kosovtzeva A. Cardiometabolic Risk Factors and HealthRelated Quality of Life in Adolescents with Obesity. Child Obes. 2017 Dec;13(6):499-506. doi: 10.1089/chi.2016.0330.

12. Schwimmer JB, Burwinkle TM, Varni JW. Health-related quality of life of severely obese children and adolescents. JAMA. 2003 Apr 9;289(14):1813-9. doi: 10.1001/ jama.289.14.1813.

13. Jalali-Farahani S, Shojaei FA, Parvin P, Amiri P. Comparison of health-related quality of life (HRQoL) among healthy, obese and chronically ill Iranian children. BMC Public Health. 2018 Dec 4;18(1):1337. doi: 10.1186/s12889018-6239-2.

14. Vallis M. Quality of life and psychological well-being in obesity management: improving the odds of success by managing distress. Int J Clin Pract. 2016 Mar;70(3):196-205. doi: $10.1111 /$ ijcp. 12765 .

15. Lazarevich I, Irigoyen Camacho ME, Velázquez-Alva MDC, Zepeda Zepeda M. Relationship among obesity, depression, and emotional eating in young adults. Appetite. 2016 Dec 1;107:639-644. doi: 10.1016/j.appet.2016.09.011.
16. Puder JJ, Munsch S. Psychological correlates of childhood obesity. Int J Obes (Lond). 2010 Dec;34 Suppl 2:S37-43. doi: 10.1038/ijo.2010.238.

17. KhaninYL. A brief guide to the use of reactive and personal anxiety scale by Ch.D. Spielberger. Leningrad: LNIITEK; 1976. [In Russian].

18. Khvan AA, Zaitsev YA, Kuznetsova YA. [Standardization of the A. Bass and A. Darki questionnaire]. Psychological diagnosis. 2008;1:35-58.[In Russian].

19. Sobchik LN. Psychodiagnostics in medicine. Practical guide. Moscow: Borgis. 2007. [In Russian].

20. Varni JW, Burwinkle TM, Seid M, Skarr D. The PedsQL 4.0 as a pediatric population health measure: feasibility, reliability, and validity. Ambul Pediatr. 2003 Nov-Dec;3(6):329-41. doi: 10.1367/1539-4409(2003)003<0329:tpaapp >2.0.co;2.

21. van Ittersum $\mathrm{K}$, Wansink B. Extraverted children are more biased by bowl sizes than introverts. PLoS One. 2013 Oct 30;8(10):e78224. doi: 10.1371/journal.pone.0078224.

22. Eysenck HJ. Biological dimensions of personality. Handbook of personality: Theory and research. New York: Guilford Press; 1990.

23. Herman CP, Koenig-Nobert S, Peterson JB, Polivy J. Matching effects on eating: do individual differences make a difference? Appetite. 2005 Oct;45(2):108-9. doi: 10.1016/j. appet.2005.03.013.

24. Muraven M, Baumeister RF. Self-regulation and depletion of limited resources: does self-control resemble a muscle? Psychol Bull. 2000 Mar;126(2):247-59. doi: 10.1037/00332909.126.2.247.

25. Stice E, Spoor S, Ng J, Zald DH. Relation of obesity to consummatory and anticipatory food reward. Physiol Behav. 2009 Jul 14;97(5):551-60. doi: 10.1016/j. physbeh.2009.03.020. Epub 2009 Mar 27.

26. Hasler G, Pine DS, Kleinbaum DG, Gamma A, Luckenbaugh D, Ajdacic V, Eich D, Rössler W, Angst J. Depressive symptoms during childhood and adult obesity: the Zurich Cohort Study. Mol Psychiatry. 2005 Sep;10(9):842-50. doi: 10.1038/sj.mp.4001671.

27. Boodai SA, Reilly JJ. Health related quality of life of obese adolescents in Kuwait. BMC Pediatr. 2013 Jul 11;13:105. doi: 10.1186/1471-2431-13-105.

28. Keating CL, Moodie ML, Swinburn BA. The healthrelated quality of life of overweight and obese adolescents-a study measuring body mass index and adolescent-reported perceptions. Int J Pediatr Obes. 2011 Oct;6(5-6):434-41. doi: 10.3109/17477166.2011.590197.

29. Riazi A, Shakoor S, Dundas I, Eiser C, McKenzie SA. Health-related quality of life in a clinical sample of obese children and adolescents. Health Qual Life Outcomes. 2010 Nov 15;8:134. doi: 10.1186/1477-7525-8-134.

30. Zeller M, Kirk S, Claytor R, Khoury P, Grieme J, Santangelo M, Daniels S. Predictors of attrition from a pediatric weight management program. J Pediatr. 2004 Apr;144(4):46670. doi: 10.1016/j.jpeds.2003.12.031. 